\title{
Estimation of Cardiodepressant Potency of Nadolol, Alprenolol, Propranolol and Pindolol, $\beta$-Blocking Agents, in Heart-Lung Preparation and Blood-Perfused Excised Papillary Muscle Preparation of the Dog
}

\author{
Hiroshi ONO, Yukiko KANAZAWA, Naoki O'HARA and Koroku HASHIMOTO \\ Hatano Research Institute. Food and Drug Safety Ceriter. \\ 729-5 Ochiai, Hadano. Kariagawa 257, Japan
}

Accepted September 6, 1984

\begin{abstract}
Direct cardiodepressant potency of nadolol was determined by comparing its effect with those of alprenolol, propranolol and pindolol, in both heartlung preparation and blood-perfused papillary muscle preparation of the dog. In the heart-lung preparation, mean $50 \% \beta$-blocking doses of the $\beta$-blockers to inhibit the positive chronotropic action of isoproterenol were $3.75 \mu \mathrm{g}$ for nadolol, $12.5 \mu \mathrm{g}$ for alprenolol, $9.6 \mu \mathrm{g}$ for propranolol and $1.6 \mu \mathrm{g}$ for pindolol. Alprenolol and propranolol in a dose of $10 \mathrm{mg}$ shifted the cardiac function curves rightward and downward, while nadolol and pindolol in the dose of $10 \mathrm{mg}$ did not shift the cardiac function curves. In the blood-perfused papillary muscle preparation, mean $50 \% \beta$-blocking doses of the $\beta$-blockers, administered i.v. to the donor dog, to inhibit the positive inotropic action of isoproterenol were $9.1 \mu \mathrm{g} / \mathrm{kg}$ for nadolol, $56.6 \mu \mathrm{g} / \mathrm{kg}$ for alprenolol, $68.3 \mu \mathrm{g} / \mathrm{kg}$ for propranolol and $8.1 \mu \mathrm{g} / \mathrm{kg}$ for pindolol. Nadolol did not depress the contractile force in doses up to $1 \mathrm{mg} / \mathrm{kg}$ given i.v. or doses up to $10 \mathrm{mg}$ given intra-arterially (i.a.) close to the preparation. Alprenolol and propranolol exerted the dose-related negative inotropic effects, when larger doses (30-300 $\mu \mathrm{g}$ ) were injected i.a. Thus, it is confirmed that nadolol virtually possesses no direct cardiodepressant activity and also that the depressant activity is exerted only by large doses of the other $\beta$-blockers.
\end{abstract}

A large number of $\beta$-blockers have been introduced, and their clinical usefulness has been mostly established. Hence, newly introduced $\beta$-blockers should possess some unique property to rationalize their development. Nadolol is a relatively new $\beta$-blocker whose distinguishing properties have been claimed to be that 1 ) its $\beta$-blocking potency is higher than propranolol, 2) its activity is very long-lasting and it undergoes little metabolic degradation, and 3 ) it has no cardiodepressant activity (1). In addition, it has no intrinsic sympathomimetic activity, and therefore, it is classified as one of the I-4 blockers together with sotalol and timolol (2).

There are several unsettled problems regarding nadolol, however. First, there is a discrepancy in the $\beta$-blocking potency of nadolol. According to Goodman and Gilman's textbook (3), nadolol has $1 / 2$ the potency of propranolol, whereas according to other reviewers, it is 1.5 times (4) or 2-4 times (5) as potent as propranolol. Secondly, it must be confirmed that nadolol is entirely free from direct cardiodepressant activity, because precipitation of heart failure is one of the most serious adverse effects of $\beta$-blockers. The potential of $\beta$-blockers to precipitate heart failure is a controversial problem; it is still unclear whether heart failure is induced by their direct cardiodepressant action or by their $\beta$-blocking action, since the latter may interfere with the compensating effects of the sympathetic nervous system and of circulating catecholamines in the patients 
with depressed cardiac function. Though in vitro pharmacological studies clearly have shown that nadolol lacks and propranolol possesses direct inhibitory activity on the myocardium $(1,6)$, the information is rather indirect in terms of clinical significance, because there are no quantitative studies concerning the relation between the clinical effective dose, $\beta$-blocking dose, and the cardiodepressant dose.

It seems that most of the discrepancies regarding the $\beta$-blocking and cardiodepressant actions of $\beta$-blockers have resulted from differences in the pharmacological methods used. In the present study, we have confirmed lack of the depressant activity of nadolol in the heart-lung preparation and bloodperfused myocardial preparation of the dog. by comparing its effect with those of other representative $\beta$-blockers, alprenolol, propranolol and pindolol. The $\beta$-blockers studied in this experiment were selected from each group of non-cardioselective $\beta$-blockers classified by Prichard (2). Alprenolol is a representative of the non-selective $\beta$ blockers having intrinsic sympathomimetic activity (ISA) and membrane stabilizing activity (MSA), propranolol is a representative of the $\beta$-blockers having MSA and no ISA, and pindolol is a representative of the $\beta$-blockers having ISA and no MSA. Nadolol belongs to the 4 th class of non-selective $\beta$ blockers and possesses neither ISA nor MSA.

\section{Materials and Methods}

\section{Procedures}

1. Heart-lung preparation of the dog: Heart-lung preparation of the dog was made according to the method originated by Starling, with minor modifications that we have described in detail elsewhere (7). Mongrel dogs $(8.0-14.0 \mathrm{~kg})$ were anesthetized with $30 \mathrm{mg} / \mathrm{kg}$ of pentobarbital sodium, i.v., and the heart-lung preparation was made under artificial respiration using room air. The space of the extracorporeal circuit was filled with heparinized blood exsanguinated from another dog under light pentobarbital anesthesia. A Morawitz's cannula was inserted to the coronary sinus to measure the coronary blood flow, being assumed to be $70 \%$ of the total coronary blood flow. The cardiac output was calculated as the sum of the aortic flow and the coronary flow. Two electromagnetic flowmeters (Narco, RT500) were used to measure the aortic and coronary blood flow rates. The left ventricular pressure was measured with a Statham transducer (P23Db) through a cannula perforating the frontal wall of the ventricle, and the rate of change in the pressure $(\mathrm{dp} / \mathrm{dt})$ was obtained by electrical differentiation. These values were recorded on directly writing recti-linear recorders (San-ei, 8S53).

$\beta$-Blocking potencies of the $\beta$-blockers were estimated by the degree of inhibition of the positive chronotropic effect of isoproterenol by a cumulative administration of a $\beta$-blocker.

Cardiac performance was evaluated by the cardiac function curve obtained by the competence test, in which the blood level of the venous reservoir was raised stepwise by 5, 10 and $15 \mathrm{~cm}$ above the basal height from the table surface. Cardiac output was plotted against the right atrial pressure to make the cardiac function curve, and the maximal rate of increase in the left ventricular pressure (dp/dt max) was plotted against the left ventricular end-diastolic pressure (LVEDP) to make another function curve for the left ventricular contractility.

Cardiodepressant action of a drug was evaluated by competence tests carried out at 2 and $10 \mathrm{~min}$ after the administration of $10 \mathrm{mg}$ of one of the $\beta$-blockers to the heart. In the previous study (7), the dose response study was performed to evaluate the effect of drugs. The dose response study, however, takes so much time that the heart failure occur spontaneously. Therefore, it is difficult to determine whether the resulting heart failure is due to "spontaneous" deterioration or due to the influence of a drug. The natural course of cardiac function was also investigated in the previous study (7). The cardiac function was maintained unchanged from the initial control until $90 \mathrm{~min}$, though after $120 \mathrm{~min}$, it showed some deterioration as reflected by a shift of the function curve from the control. In the present study, the dose of a $\beta$-blocker was limited to $10 \mathrm{mg}$ each and the observation was made within 60 min after the preparation was 
set up.

2. Blood-perfused excised papillary muscle preparation of the dog: Mongrel dogs of either sex weighing $8.6-14.0 \mathrm{~kg}$ were anesthetized with pentobarbital sodium (30 $\mathrm{mg} / \mathrm{kg}$, i.v.) and exsanguinated after heparinizing the whole body. The heart was excised and the papillary muscle preparation was made as described by Endoh and Hashimoto (8). The anterior septal artery was cannulated to perfuse the right ventricular anterior papillary muscle including the interventricular septal tissue surrounding it. The preparation was perfused with arterial blood of a supporting dog at the perfusion pressure of $100 \mathrm{mmHg}$ by the use of a Harvard peristaltic pump and a Starling's pneumatic resistance. Supporting dogs $(12.0-30.5 \mathrm{~kg}$ ) were anesthetized with injection of $2-3 \mathrm{ml} /$ $\mathrm{kg}$ of a mixture solution of $\alpha$-chloralose (25 $\mathrm{mg} / \mathrm{ml})$ and urethane $(250 \mathrm{mg} / \mathrm{ml})$ intravenously at the cephalic vein, preceded by sedative treatment with morphine hydrochloride (2 mg/kg. s.c.). Supplemental doses of chloralose-urethane were given when necessary during the experiment. Heparin sodium was used to inhibit blood coagulation. The papillary muscle preparation was electrically driven with $2 \mathrm{~Hz}$ frequency and the isometric tension development of the papillary muscle (with a Grass strain gauge FT03C) and the blood flow rate through the preparation (with a Narco electromagnetic flowmeter RT500) were measured and recorded on a directly writing rectilinear recorder (San-ei, 8S53).

Drugs were administered intra-arterially close to the papillary muscle or intravenously to the supporting dog. Isoproterenol or a $\beta$ blocker was injected at a rubber tubing attached to the arterial cannula in a volume of 10-30 $\mu \mathrm{l}$ over $4 \mathrm{sec}$. To estimate $\beta$ blocking activity, a $\beta$-blocker was administered intravenously to the supporting dog with cumulative dosing in an increasing manner.

\section{Drugs}

Drugs used in this study were as follows: Nadolol (Squibb-Dainippon), dl-alprenolol hydrochloride (Astra-Fujisawa), pindolol (Sandoz-Sankyo), dl-propranolol hydrochloride (Sigma), I-isoproterenol (Sigma), heparin sodium (Sigma), pentobarbital sodium (Tokyo Kasei), morphine hydrochloride (Sankyo), $\alpha$-chloralose (Wako) and urethane (Wako). All drug dosages other than heparin and anesthetics will be expressed as bases.

\section{Statistics}

Data will be described as the mean \pm standard error. Significance of the difference between the means was evaluated by Student's $t$-test when the two variances were not different significantly by the $F$-test $(P<0.05)$, while the $t$-test was done according to Cochrane-Cox when the two variances were significantly different.

\section{Results}

\section{Heart-lung preparation}

1. Comparison of the $\beta$-blocking potencies of the four $\beta$-blockers: $\beta$-Blocking potencies of the four $\beta$-blockers, nadolol, alprenolol, propranolol and pindolol, to inhibit the positive chronotropic effect of $0.03-0.3 \mu \mathrm{g}$ of isoproterenol were compared in the canine heart-lung preparation. The dose of isoproterenol that had produced 20-50\% increase in heart rate was selected and administered repeatedly, after $\beta$-blocker administration. Figure 1 shows the mean doses of nadolol, alprenolol, propranolol and

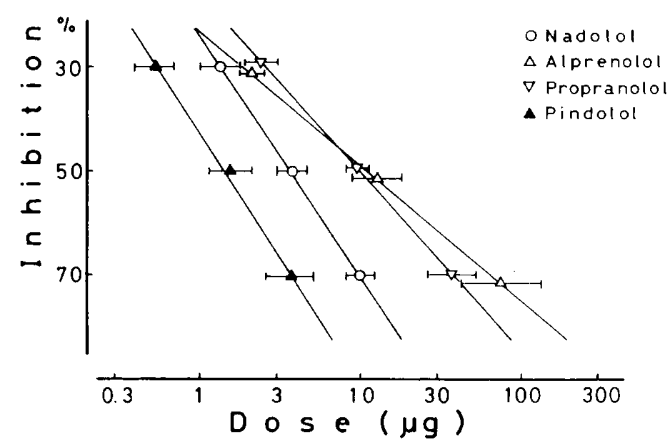

Fig. 1. Dose-response curves for nadolol, alprenolol, propranolol and pindolol to inhibit the positive chronotropic effect of isoproterenol in heartlung preparation of the dog. The logarithms of the dose associated with the 30,50 and $70 \% \beta$-blocking were obtained by interpolating each of the doseresponse curves. Each symbol and horizontal bars attached to it show the mean and standard error. respectively, of these logarithms. $N=5$ for each drug. 
pindolol to induce 30,50 and $70 \% \beta$ blocking action.

The dose-response curves for nadolol. pindolol and propranolol, in doses having 30 and $70 \% \beta$-blocking action, were moderate and similar in steepness, while that for alprenolol was not so steep but rather creeping. Doses of the $\beta$-blockers to inhibit the positive chronotropic effect of isoproterenol by $50 \%$ (ID50) were $3.8(3.0-$ 11.2) $\mu \mathrm{g}$ for nadolol, $12.5(8.7-18.0) \mu \mathrm{g}$ for alprenolol, $9.6(8.2-11.2) \mu \mathrm{g}$ for propranolol and $1.6(1.2-2.1) \mu \mathrm{g}$ for pindolol (mean and standard error of 5 observations for every drug).

2 . Effects of the $\beta$-blockers on performance of the heart-lung preparation: Administration of $10 \mathrm{mg}$ of nadolol did not influence the cardiac function curves of the heart-lung preparation (Fig. 2). On the contrary, $10 \mathrm{mg}$ of alprenolol induced a significant inhibition of the cardiac performance and shifted the cardiac function curve to the right and downward. The shift was manifest at $2 \mathrm{~min}$
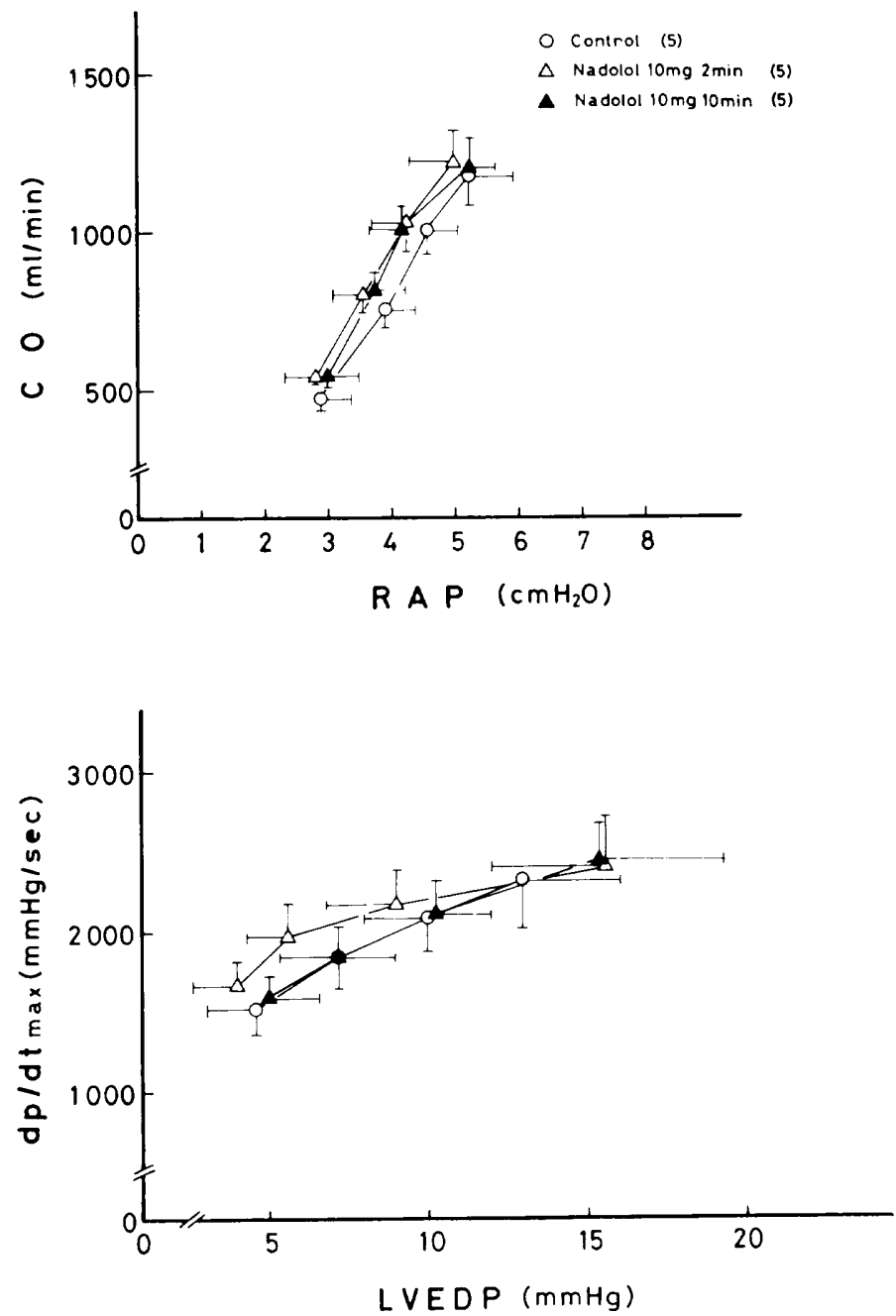

Fig. 2. Cardiac function curves and left ventricular contractile function curves before and 2 and 10 min after administration of $10 \mathrm{mg}$ of nadolol. CO: cardiac output, RAP: right atria! pressure, $\mathrm{dp} / \mathrm{dtmax}$ : maximal rate of increase in the left ventricular pressure, LVEDP: left ventricular end-diastolic pressure. Numbers in parentheses indicate numbers of experiments. 
after the administration and advanced a little further at $10 \mathrm{~min}$. Contractile function of the left ventricle was also inhibited, and the function curve was shifted to the right and became flattened (Fig. 3). Results with propranolol on the heart-lung preparation were essentially the same as those of alprenolol, though statistical analysis did not show significant differences, except for the decrease in cardiac output response to the competence test after $10 \mathrm{~min}$ of propranolol administration (Fig. 4). Pindolol, as well as nadolol, did not show any depressant effect on the heart-lung preparation at a dose of $10 \mathrm{mg}$, as shown in Fig. 5. Pindolol produced, on the other hand, slight leftward and upward shifts of the cardiac function curve and the left ventricular contractile function curve, though the shifts were not significant, indicating that pindolol has intrinsic sympathomimetic activity.

These investigations were completed within 60 min after the preparation was set up. II. Blood-perfused excised papillary muscle preparation

1. Comparison of the $\boldsymbol{\beta}$-blocking potencies: The developed tension of the papillary muscle preparation at the beginning of the measure-
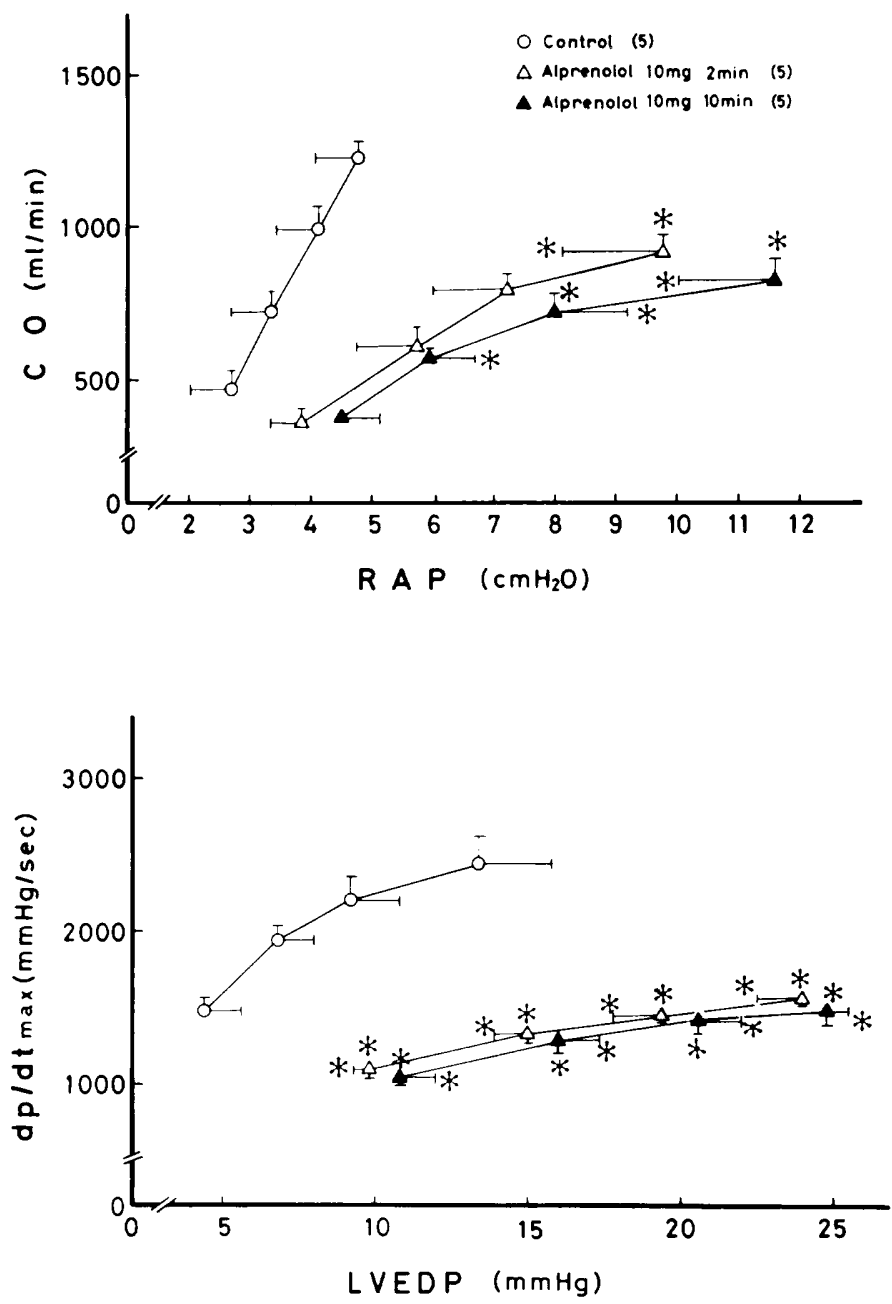

Fig. 3. Effects of alprenolol on cardiac function curves and left ventricular contractile curves of heartlung preparation of the dog. Abbreviations are the same as in Fig. 2. Asterisk $\left({ }^{*}\right)$ shows that the difference from the control value is statistically significant at $P<0.05, N=5$. 

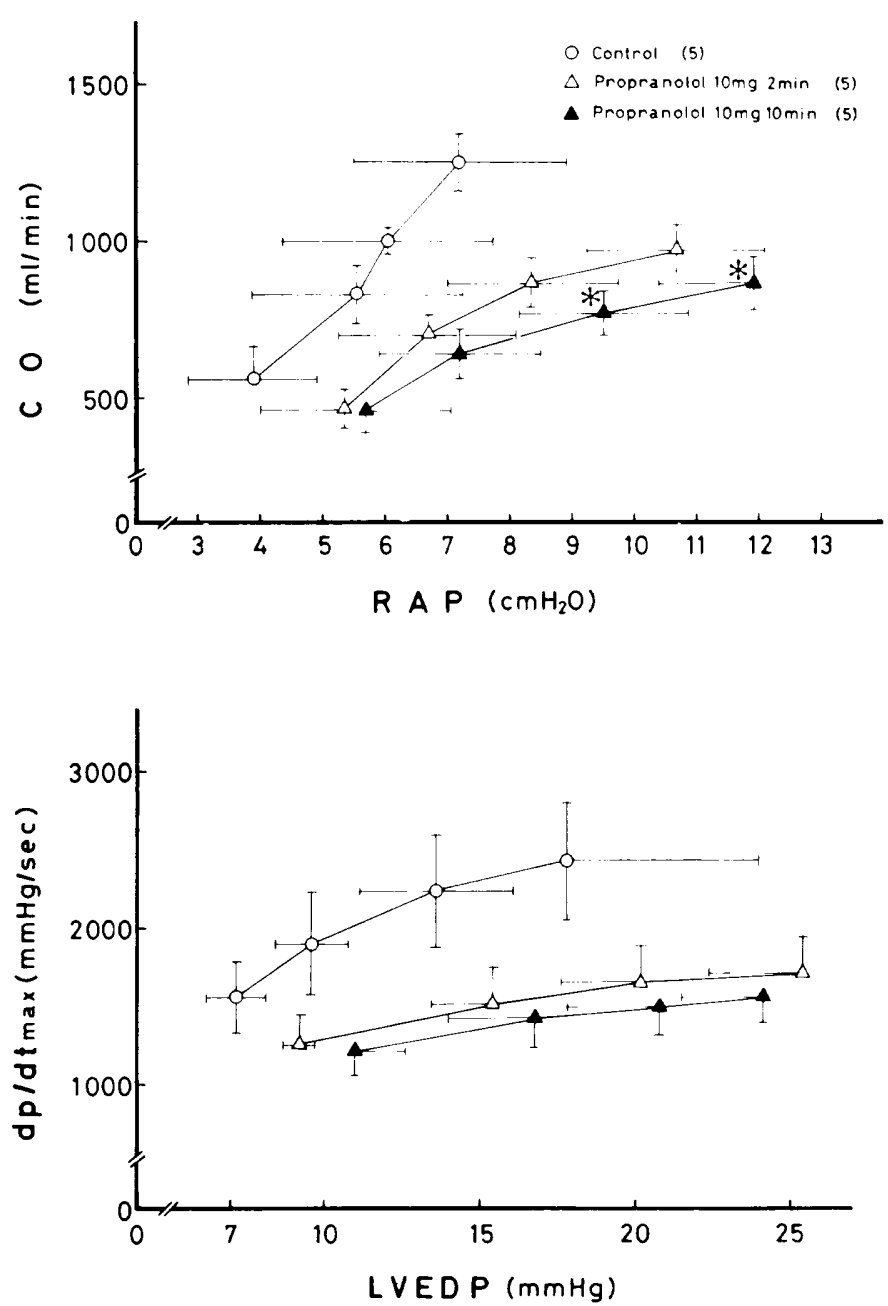

Fig. 4. Effect of propranolol on cardiac function curves and left ventricular contractile function curves of heart-lung preparation of the dog. Abbreviations are the same as in Fig. $2 .{ }^{*}: P<0.05, N=5$.

ment was $3.8 \pm 0.1 \mathrm{~g}(\mathrm{~N}=20)$ when it was driven with $2 \mathrm{~Hz}$ frequency and preloaded to show the resting tension of $1.0 \mathrm{~g}$. The initial blood flow rate through the preparation was $9.6 \pm 1.1 \mathrm{ml} / \mathrm{min}$.

$\beta$-Blocking potencies of nadolol, alprenolol, propranolol and pindolol injected intravenously to the supporting dog were estimated from the inhibitory effect on the positive inotropic effect of isoproterenol $(0.001-0.1 \mu \mathrm{g})$ injected intra-arterially close to the preparation. Dose of isoproterenol to produce about $100 \%$ increase in papillary muscle tension was selected and given repeatedly after $\beta$-blocker administration.

Nadolol $(1-1000 \mu \mathrm{g} / \mathrm{kg})$ did not show any direct effect on the papillary muscle contraction, but exerted dose-related inhibition of the inotropic effect of isoproterenol. Other $\beta$-blockers, alprenolol $(1-1000 \mu \mathrm{g} / \mathrm{kg})$, propranolol (1-1000 $\mu \mathrm{g} / \mathrm{kg})$ and pindolol (1$300 \mathrm{~kg} / \mathrm{kg}$ ), also showed dose-related $\beta$ blocking activities. Figure 6 shows the doses of the $\beta$-blockers to inhibit the inotropic effect of isoproterenol in the papillary muscle preparation, tracing the dose for 30,50 and $70 \% \beta$-blockade. All the dose-response curves for the four $\beta$-blockers were nearly 

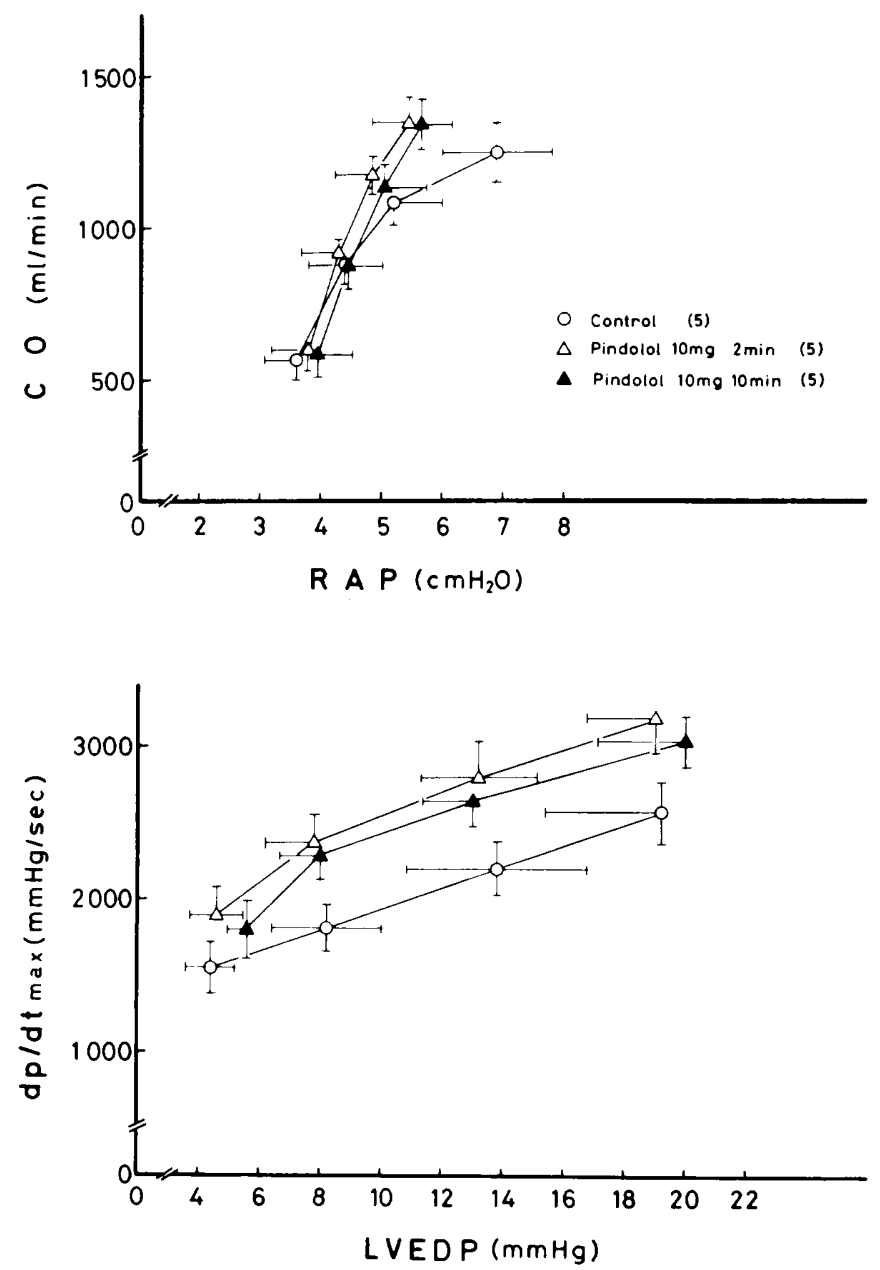

Fig. 5. Effect of pindolol on cardiac function curves of heart-lung preparation of the dog. Abbreviations are the same as in Fig. 2. $\mathrm{N}=5$.

parallel. Nadolol and pindolol were almost equipotent and about 10 times as potent as the other two $\beta$-blockers, alprenolol and propranolol, which were also equipotent to each other. Doses of the $\beta$-blockers to inhibit the positive inotropic effect of isoproterenol by $50 \%$ were $9.1 \quad(8.3-10.0) \mu \mathrm{g} / \mathrm{kg}$ for nadolol, $56.6 \quad(36.6-87.3) \mu \mathrm{g} / \mathrm{kg}$ for alprenolol. $68.3 \quad(49.1-95.3) \mu \mathrm{g} / \mathrm{kg}$ for propranolol and $8.1(5.3-12.5) \mu \mathrm{g} / \mathrm{kg}$ for pindolol (mean and standard error of 5 observations for each drug).

2. Myocardial depressant activities: Direct myocardial depressant effects of alprenolol and propranolol in the blood-perfused papillary muscle preparation were observed by high doses of intravenous administration. A large intravenous dose of propranolol (1 $\mathrm{mg} / \mathrm{kg}$ ) and of alprenolol (1 $\mathrm{mg} / \mathrm{kg})$ decreased the developed tension of the papillary muscle by about $20 \%$ and $30 \%$. respectively. Changes of the tension after the intravenous administration of $1 \mathrm{mg} / \mathrm{kg}$ of nadolol and pindolol were within $5 \%$. Then, the $\beta$-blockers were injected intraarterially close to the papillary muscle to assess the direct myocardial action. Nadolol, 30-300 $\mu \mathrm{g}$, produced an insignificant decrease in the tension development of the papillary muscle. Nadolol, 1-30 mg, produced 
indefinite changes in the papillary muscle. increases or decreases of the tension develop-

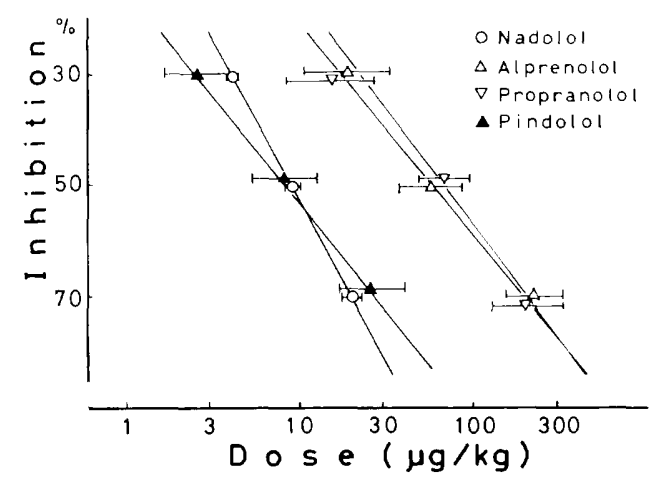

Fig. 6. Dose-response curves for intravenous nadolol, alprenolol, propranolol and pindolol to inhibit the positive inotropic effect of isoproterenol. i.a., in blood-perfused excised papillary muscle preparation of the dog. Symbols and horizontal bars attached to them are the means and standard errors. respectively, calculated on logarithmic principle. $\mathrm{N}=5$ for each drug. ment within $10 \%$ (Fig. 7)

Alprenolol and propranolol, 10-300 $\mu \mathrm{g}$. i.a., exerted dose-related negative inotropic effects in the papillary muscle preparation (Fig. 7). Pindolol, 3-30 $\mu \mathrm{g}$, produced a positive inotropic effect in the papillary muscle preparation, though doses of pindolol above $100 \mu \mathrm{g}$ produced a negative one (Fig. 7).

Summarized results of the effects of the $\beta$-blockers on the developed tension of the papillary muscle preparation are shown in Fig. 8.

Propranolol and alprenolol produced an increase in the blood flow through the papillary muscle preparation (Fig. 7). Nadolol and pindolol were not vasoactive compounds (Fig. 7).

\section{Discussion}

1. Comparison of the $\beta$-blocking potencies of the $\beta$-blockers: In the original report by Lee et al. (1), it was reported that the $\beta$ -

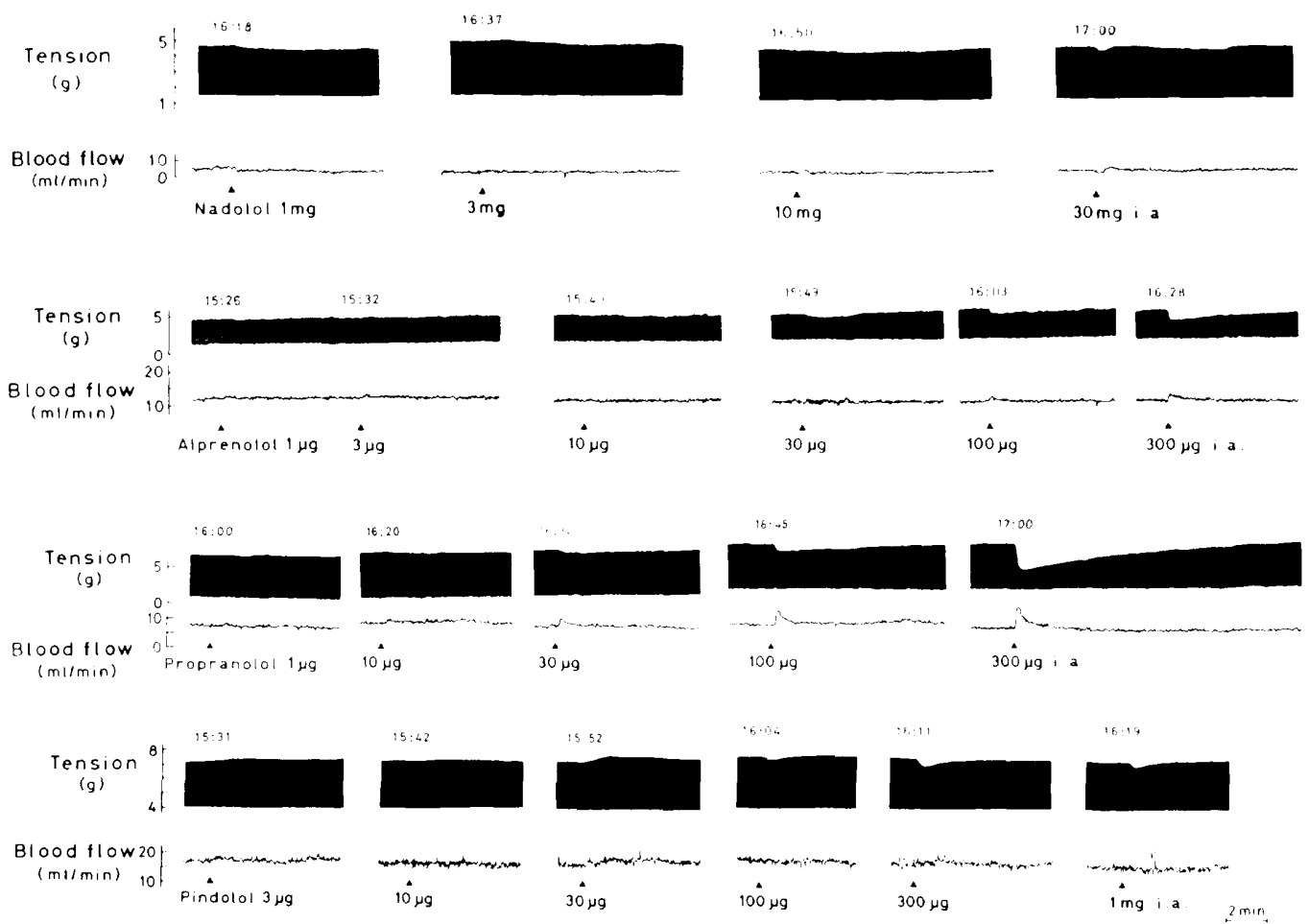

Fig. 7. Typical records showing the effects of nadolol, alprenolol, propranolol and pindolof injected intra-arterially close to the papillary muscle preparation on the tension development and the blood flow rate. 


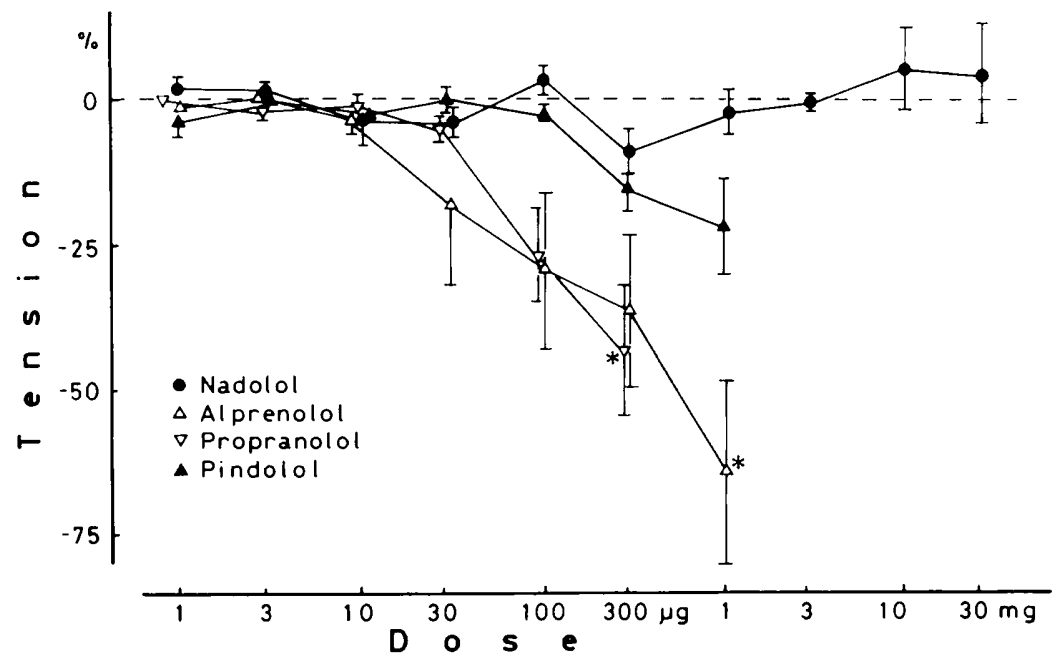

Fig. 8. Summary of the effects of nadolol, alprenolol, propranolol and pindolol injected intra-arterially close to the papillary muscle preparation of the dog. $N=5$ for each drug.

blocking potency of nadolol was $1 / 3$ that of propranolol in isolated guinea pig atria, while nadolol was 2-4 times as potent as propranolol in the anesthetized dog. On the other hand, a comparative study between nadolol and propranolol by the intravenous route in man revealed that nadolol was 6 times as potent as propranolol on a weight basis (9). Thus, it must be emphasized that potency comparisons often differ according to differences in experimental methods. In vitro experiments are decisively different from in vivo experiments in protein binding of a drug, influences of reflex and other biological modifications, or in drug metabolism. The experiments performed in the present study were both in vitro experiments with cardiac preparations: heart-lung preparation and blood-perfused papillary muscle preparation. both of which were maintained with blood.

Since heart-lung preparation has excluded the liver and kidney, the dose-response study was performed by a cumulative dosing method. It is possible that this may have lead to an erroneous result if there is a drug inactivating mechanism in the heart, lung or blood. It is unlikely, however, that such mechanisms work actively in these tissues. Doses for $50 \% \beta$-blockade thus obtained have been described in the Results. Relative potencies among the four $\beta$-blockers at $50 \%$ $\beta$-blockade were: nadolol, 1; alprenolol. 0.3; propranolol, 0.4; and pindolol, 2.3.

Blood-perfused isolated papillary muscle preparation has an advantage in that it can be used for estimation of potencies of drug administered intravenously. In this study, a dose-response curve was obtained by a repeated administration of a drug in cumulative doses, which were given with 15-60 min intervals. The whole course was completed within $3 \mathrm{hr}$. This protocol may have caused an error in the estimation due to metabolic degradation of previously administered doses. Potency of a drug that undergoes little metabolic inactivation such as nadolol (1) will be estimated as higher. Doses of the $\beta$-blockers for $50 \% \beta$-blocking thus estimated in this preparation have been described in the Results. Relative potencies were: nadolol, 1; alprenolol, 0.16; propranolol, 0.13; and pindolol, 1.1.

Thus, the $\beta$-blocking potency of nadolol was estimated to be $2.6-7.5$ times as potent as propranolol in the isolated cardiac preparations of the dog supported by blood.

In a previous study of one of the present authors (10), the potency ratio of nadolol: propranolol: pindolol was roughly $1: 0.04$ : 0.4 in the blood-perfused canine papillary muscle preparation when the $\beta$-blockers were injected intra-arterially. Here is another 
complicated problem in assessing an antagonistic potency. We now hold that the present procedure, i.e., intravenous administration of a blocking agent, is better than the previous one, intra-arterial administration. because the blocking agent will be much more easily washed out from the tissue by the fresh blood in the case of intra-arterial administration so that the receptor occupancy by the blocker may decrease much more rapidly.

2. Direct cardiodepressant action of nadolol and other $\beta$-blockers: $\beta$-Blockers are classified into groups by their properties having or not having intrinsic sympathomimetic activity (ISA) or membrane stabilizing activity (MSA). The vasodilator property is also a characteristic that distinguishes the $\beta$-blockers. Propranolol and alprenolol are vasodilators, while nadolol and pindolol are non-vasodilators. The mechanism of this action is not well understood except that it is the direct action of the drug (11). Direct cardiodepressant action of a $\beta$-blocker has been included in MSA or "quinidine-like" action, which is closely related to local anesthetic action, though the validity of the term MSA or "quinidine-like" is being questioned (12).

Substantial lack of cardiac depressant activity of nadolol was confirmed in the present study. In the heart-lung preparation. $10 \mathrm{mg}$ of nadolol showed no effect on the cardiac performance examined by the competence test. Lack of cardiodepressant action of pindolol was also demonstrated. Alprenolol and propranolol showed a definite depressant action on the function curve of the heartlung preparation, when $10 \mathrm{mg}$ of these $\beta$ blockers was administered. Previously, we had made a dose-response study on propranolol and pindolol in the canine heartlung preparation (7). The shift of the function curve after $1 \mathrm{mg}$ of propranolol was not statistically significant and was not recognized after $1 \mathrm{mg}$ of pindolol in the previous study (7).

Even in the blood-perfused papillary muscle preparation, nadolol did not show the direct depressant action when it was injected up to $10 \mathrm{mg}$, i.a., close to the preparation. Propranolol produced $30 \%$ depression in the papillary muscle tension development with $0.1 \mathrm{mg}$, i.a., or with $1 \mathrm{mg} / \mathrm{kg}$, i.v. Thus, it is estimated that even with propranolol and alprenolol, direct cardiodepressant activity is exerted with doses about 15 times as large as the $50 \% \beta$-blocking doses.

Kaumann and Blinks (13) studied the depressant effect of $\beta$-blockers on isolated cardiac preparations of guinea pig and kitten in physiological salt solution and reported that the depressant effect was exerted with concentrations above $10^{-6} \mathrm{M}$ by most of the $\beta$-blockers possessing this activity including $\mathrm{dl}$-propranolol, dl-alprenolol and dl-pindolol, while the equilibrium dissociation constants $\left(K_{B}\right)$ for these $\beta$-blockers were between 8 and 9 (14).

Precipitation of heart failure in patients with cardiac diseases is a serious problem though the incidence is low (15). It is reported that the incidence of heart failure induction is not different among various $\beta$-blockers regardless of their cardiodepressant activity (16). Then, the results of the present study being taken into account, the mechanism of precipitating heart failure is considered to be the $\beta$ blocking action itself and not the direct cardiodepressant action that only some $\beta$ blockers possess, and that is exerted only at a much higher dose range than the $\beta$ blocking dose. Consequently, if heart failure is induced by the $\beta$-blocking action per se, the same amount of caution and care must by taken in every $\beta$-blocker therapy. However, since nadolol lacks direct cardiodepressant activity, it seems favorable for clinical use for cardiac patients, especially in the state of limited cardiac reserve, because even weak cardiodepressant activity may become manifest in some diseased hearts.

Contribution of the ISA of a $\beta$-blocker to this problem is also a point of controversy. In the heart-lung preparation, pindolol showed a stimulatory effect on the left ventricular contraction, but it did not shift the normal cardiac function curve (Fig. 5). Alprenolol, another $\beta$-blocker having ISA, deteriorated the cardiac function and failed to increase the left ventricular contractile force. These results, however, were obtained with very large doses, and conclusive statements should be reserved. In the previous 
study (7), the effects of pindolol and carteolol (which had also ISA) have been studied on the function of canine heart-lung preparation treated with pentobarbital. Both pindolol and carteolol, 0.1, 1 and $10 \mathrm{mg}$ by cumulative administration, failed to improve the compromised cardiac function.

Acknowledgements: The authors are grateful to Dainippon Pharmaceutical Co. for supplying nadolol. Technical contribution of Mr. K. Shukunobe to this study is highly appreciated.

\section{References}

1 Lee, R.J., Evans, S.H. and Laffan, R.J.: Pharmacology of nadolol (SQ 11725), a $\beta$-adrenergic antagonist lacking direct myocardial depression. Eur. J. Pharmacol. 33, 371-382 (1975)

2 Prichard, B.N.C.: $\beta$-Adrenergic receptor blockade in hypertension, past, present and future. Br. J. Clin. Pharmacol. 26, 162-166 (1979)

3 Goodman Gilman, A., Goodman, L.S. and Gilman, A.: The Pharmacological Basis of Therapeutics. 6th ed., p. 188-197. Macmillan. New York (1980)

4 Jackson, G. and Harrison, D.C.: Adverse effects of beta-adrenergic blocking drugs. In Druginduced Heart Disease, Edited by Bristow, M.R. p. 323-339, Elsevier/North Hollar,d Biomedical Press, Amsterdam (1980)

5 Bowman, W.C. and Rand, M.J.: Textbook of Pharmacology. 2nd ed., p. 11-48, Blackwell Scientific Publisher, Oxford (1980)

6 Evans, D.B., Parham, C.S. and Laffan, R.J.: Nonspecific myocardial depression by betaadrenergic receptor blockers in normal and compromised myocardium. Arch. Int. Pharmacodyn. Ther. 240, 240-248 (1979)

7 Ono, $\mathrm{H}$. and $\mathrm{O}$ Hara, N.: A study on the cardiodepressant action of a $\beta$-glocking agent carteolol in heart-lung preparation of the dog. Japan. Circ. J. 48, 1030-1044 (1984)
8 Endoh, M. and Hashimoto, K.: Pharmacological evidence of autonomic nerve activity in canine papillary muscle. Am. J. Physiol. 218, 1459 1463 (1970)

9 LeWinter, M.M., Curtis, G.P., Engler, R.L., Shabetai, R. and Verba, J.: Effects of equiblocking doses of nadolol arid propranolol on left ventricular performance. Clin. Pharmacol. Ther. 26. 162-166 (1979)

10 Hashimoto, K., Kimura, T. and Yabuuchi, Y.: Comparison of newly synthetized $\beta$-adrenergic blockers, OPC 1085 and SO 11725, with pindolol and propranolol in the blood-perfused canine SA node and papillary muscle preparations. Japan. J. Pharmacol. 26, 504-507 (1976)

11 Himori, N., Izumi, A. and Ishimori, T.: Analysis of the vasodilator action of alprenolol. Eur. J. Pharmacol. 47, 341-350 (1978)

12 Smith, H.J.: The need to redefine membrane stabilizing activity of beta-adrenergic receptor antagonists. J. Mol. Cell. Cardiol. 14, 495-500 (1982)

13 Kaumann, A.J. and Blinks, J.R.: Stimulant and depressant effects of $\beta$-adrenoceptor blocking agents on isolated heart muscle. Naunyn Schmiedebergs Arch. Pharmacol. 311, 205-218 (1980)

14 Kaumann, A.J., Mclnerny, T.K., Gilmour, D.P. and Blinks, J.R.: Comparative assessment of $\beta$-adrenoceptor blocking agents as simple competitive antagonists in isolated heart muscle. Naunyn Schmiedebergs Arch. Pharmacol. 311, 219-236 (1980)

15 Greenblatt, D.J. and Koch-Weser, J.: Adverse reactions to propranolol in hospitalized medical patients: A report from the Boston Collaborative Drug Surveillance Program. Am. Heart J. 86 , 478-484 (1973)

16 Friedman, L.M.: How do the beta blockers compare in type, frequency and severity of their adverse effect? Circulation 67, Supp. I, I-89 (1983) 